\begin{tabular}{|c|l|}
\hline Title & Mechanism of surface conduction in the vicinity of Schottky gates on A IGaN/GaN heterostructures \\
\hline Author(s) & Kotani, Junji; Tajima, Masafumi; Kasai, Seiya; Hashizume, Tamotsu \\
\hline Citation & $\begin{array}{l}\text { A pplied Physics Letters, 91/9), 093501 } \\
\text { https://doi.org/L0.1063/2775834 }\end{array}$ \\
\hline Issue Date & $2007-08$-27 \\
\hline Doc URL & http://hdl.handle.net/2115/29892 \\
\hline Rights & $\begin{array}{l}\text { Copyright 2007 A merican Institute of Physics. This article may be downloaded for personal use only. A ny other use } \\
\text { requires prior permission of the author and the A merican Institute of Physics. }\end{array}$ \\
\hline Type & article \\
\hline File Information & APL91-09.pdf \\
\hline
\end{tabular}

Instructions for use 


\title{
Mechanism of surface conduction in the vicinity of Schottky gates on AIGaN/GaN heterostructures
}

\author{
Junji Kotani, a) Masafumi Tajima, Seiya Kasai, and Tamotsu Hashizume \\ Research Center for Integrated Quantum Electronics (RCIQE), Hokkaido University, \\ Sapporo 060-8628, Japan
}

(Received 14 June 2007; accepted 3 August 2007; published online 28 August 2007)

\begin{abstract}
Lateral surface leakage current $\left(I_{s}\right)$ on an $\mathrm{AlGaN} / \mathrm{GaN}$ heterostructure was systematically investigated by using a two-parallel gate structure with a gap distance $\left(L_{\mathrm{GG}}\right)$ of $200 \mathrm{~nm}-5 \mu \mathrm{m}$. The surface current $I_{s}$ systematically increased as $L_{\mathrm{GG}}$ decreased. A simple resistive layer conduction that should show $1 / L_{\mathrm{GG}}$ dependence failed to account for the drastic increase in $I_{s}$ when $L_{\mathrm{GG}}$ was reduced to less than $1 \mu \mathrm{m}$. However, no dependence on $L_{\mathrm{GG}}$ was seen in vertical current that flows in the Schottky interface. The $I_{s}$ showed a clear temperature dependence proportional to $\exp \left(-T^{-1 / 3}\right)$, indicating two-dimensional variable-range hopping through high-density surface electronic states in $\mathrm{AlGaN}$. A pronounced reduction in surface current of almost four orders of magnitude was observed in a sample with $\mathrm{SiN}_{x}$ passivation. (C) 2007 American Institute of Physics.

[DOI: $10.1063 / 1.2775834]$
\end{abstract}

Schottky gates on AlGaN/GaN high-electron-mobility transistors (HEMTs) are being reduced to the nanometerscale level to enable operation at higher frequency. ${ }^{1-3}$ Source-gate and gate-drain spacings, as well as gate scaling, are being made narrower to reduce access resistance in AlGaN/GaN HEMTs. A level below $1 \mu \mathrm{m}$ has been achieved. ${ }^{2,3}$ In these devices, the gate leakage current includes not only one-dimensional transport vertical to the Schottky interface but also lateral electron injection to the AlGaN surface from the gate edge. ${ }^{4}$ Here, we have to pay attention to laterally injected charges to surface electronic states because they can cause instability in device operation. The first trial to investigate the surface leakage current on an AlGaN/GaN heterostructure was conducted by Tan et al. ${ }^{5}$ However, the electrode spacing used in their study was much longer than the actual source-gate and gate-drain distances of new AlGaN/GaN HEMTs, and the electrode configuration was also quite different from $\mathrm{AlGaN} / \mathrm{GaN}$ HEMTs. The surface leakage transport of $1 \mu \mathrm{m}$ from the Schottky gates has not been investigated so far in spite of its importance. We must control the surface in the vicinity of Schottky gates to fully exploit the excellent potential of $\mathrm{AlGaN} / \mathrm{GaN}$ HEMTs.

This letter describes our systematic characterization of surface leakage current in the vicinity of Schottky gates on the $\mathrm{AlGaN} / \mathrm{GaN}$ heterostructure, separating it from the vertical leakage current through the Schottky interface.

The $\mathrm{Al}_{0.27} \mathrm{Ga}_{0.73} \mathrm{~N} / \mathrm{GaN}$ heterostructure used for this study was grown by metal organic vapor phase epitaxy on a sapphire substrate. A 25-nm-thick AlGaN barrier layer consists of $i$-AlGaN $(5 \mathrm{~nm}) / \mathrm{Si}$-doped $\left(2 \times 10^{18} \mathrm{~cm}^{-3}\right) n$-AlGaN $(15 \mathrm{~nm}) / i$-AlGaN $(5 \mathrm{~nm})$. Typical values of the electron concentration and mobility of two-dimensional electron gas (2DEG) at room temperature were $1.0 \times 10^{13} \mathrm{~cm}^{2}$ and $1380 \mathrm{~cm}^{2} / \mathrm{V} \mathrm{s}$, respectively.

Figure 1(a) shows the dual-gate structure for characterizing the surface current. We fabricated an additional Schottky gate, G2, near the main Schottky gate, G1, with an

\footnotetext{
a) Author to whom correspondence should be addressed; electronic mail: kotani@rciqe.hokudai.ac.jp
}

$L_{\mathrm{GG}}$ distance of $200 \mathrm{~nm}-5 \mu \mathrm{m}$, as shown in Fig. 1(a), to detect the lateral surface current $\left(I_{s}\right)$ separated from the vertical current $\left(I_{v}\right)$. The gate length $L_{\mathrm{G}}$ was set to $1 \mu \mathrm{m}$ in all of the devices. Isolation was carried out as part of fabricating the dual-gate structure by using electron cyclotron resonance-assisted reactive ion beam etching with a mixture of $\mathrm{CH}_{4} / \mathrm{H}_{2} / \mathrm{Ar} / \mathrm{N}_{2}$ [5/15/3/3 SCCM (SCCM denotes cubic centimeter per minute at STP)] gases. ${ }^{6}$ The $\mathrm{Ti} / \mathrm{Al} / \mathrm{Ti} / \mathrm{Au}$ Ohmic electrodes were deposited, followed by annealing at $800{ }^{\circ} \mathrm{C}$ for $1 \mathrm{~min}$ in $\mathrm{N}_{2}$ ambient. Two-parallel Schottky gates were formed using electron-beam lithography.

The measurement circuit for the surface current is schematically shown in Fig. 1(b). When a negative gate voltage of $V_{\mathrm{G}}$ is applied to $\mathrm{G} 1$, the leakage current flows in two different ways, which causes the vertical current $I_{v}$ and surface current $I_{s}$, as shown in Fig. 1(b). The $I_{v}$ indicates onedimensional current transport, vertical to the Schottky interface, and $I_{s}$ indicates surface current laterally injected from the gate edge. The arrows for $I_{v}$ and $I_{s}$ in Fig. 1(b) represent the direction of electron flow. The $I_{s}$ and $I_{v}$ are detected by the G2 electrode and Ohmic electrode via a 2DEG channel, respectively.

Figures 2(a) and 2(b) show the $I_{v}-V_{\mathrm{G}}$ and $I_{s}-V_{\mathrm{G}}$ characteristics for various values of $L_{\mathrm{GG}}$, respectively. The $I_{v}$ was mostly independent of $L_{\mathrm{GG}}$, while the $I_{s}$ systematically increased as $L_{\mathrm{GG}}$ decreased. No dependence on $L_{\mathrm{GG}}$ was observed in $I_{v}$, indicating that the vertical leakage current through Schottky interfaces is decided only by the vertical

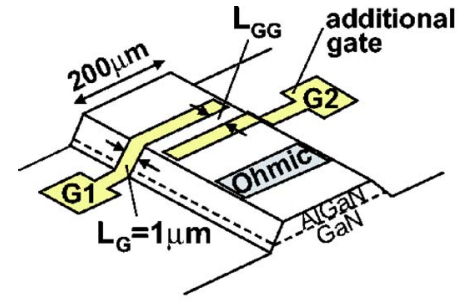

(a)

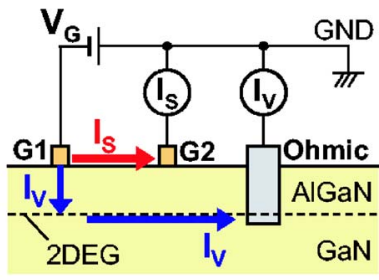

(b)
FIG. 1. (Color online) Schematic illustration of (a) dual-gate structure and (b) measurement circuit for surface current. 


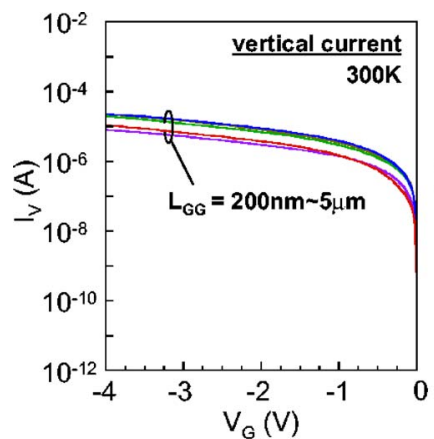

(a)

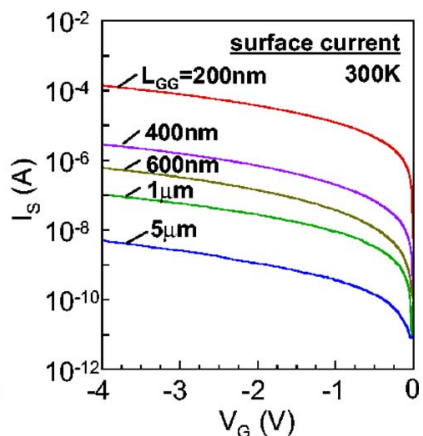

(b)

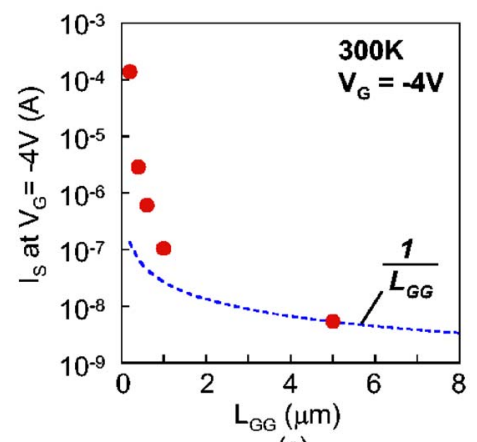

(c)

FIG. 2. (Color online) Measured (a) $I_{v}-V_{\mathrm{G}}$ and (b) $I_{s}-V_{\mathrm{G}}$ characteristics with various $L_{\mathrm{GG}}$. (c) Dependence on $L_{\mathrm{GG}}$ of $I_{s}$ at $V_{\mathrm{G}}=-4 \mathrm{~V}$.

electric field between G1 and 2DEG. The surface leakage current at $V_{\mathrm{G}}=-4 \mathrm{~V}$ is plotted in Fig. 2(c) as a function of $L_{\mathrm{GG}}$. The $I_{s}$ drastically increases when $L_{\mathrm{GG}}$ drops to less than $1 \mu \mathrm{m}$. Assuming that electrical conduction occurs in a thin resistive layer, the current between two electrodes should have $1 / L_{\mathrm{GG}}$ dependence, which is indicated by the broken line in Fig. 2(c). The experimentally observed dependence on $L_{\mathrm{GG}}$ implies that some other current transport plays an important role for $I_{s}$, especially when $L_{\mathrm{GG}}$ is less than $1 \mu \mathrm{m}$.

To obtain better insight into the transport mechanism of the vertical current and surface current, we measured the temperature dependence of $I_{v}$ and $I_{s}$. Figure 3(a) shows the $I_{s}$ and $I_{v}$ of the device with $L_{\mathrm{GG}}$ of $600 \mathrm{~nm}$ at $V_{\mathrm{G}}=-2 \mathrm{~V}$ measured at various temperatures. Extremely weak temperature dependence was observed in $I_{v}$, which is the same behavior as the leakage current in large area $\mathrm{AlGaN} / \mathrm{GaN}$ Schottky diodes. ${ }^{7}$ We investigated the leakage current transport of large area Schottky diodes with a diameter of

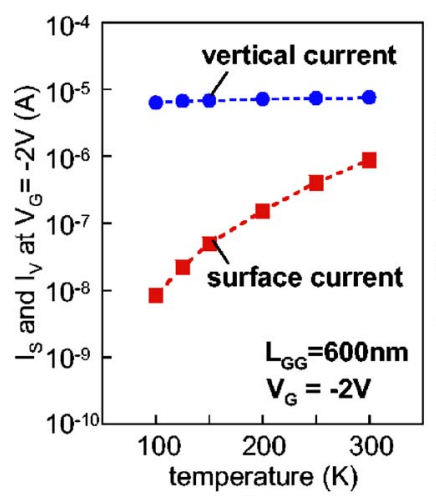

(a)

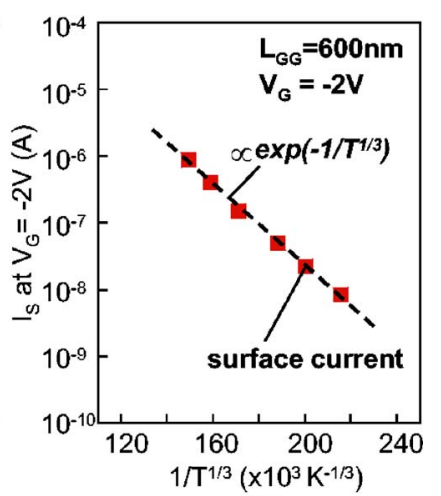

(b)
FIG. 3. (Color online) (a) Temperature dependences of $I_{s}$ and $I_{v}$ at $V_{\mathrm{G}}=-2 \mathrm{~V}$ and (b) $I_{s}$ at $V_{\mathrm{G}}=-2 \mathrm{~V}$ as a function of $1 / T^{1 / 3}$ showing a straight line, consistent with 2D-VRH conduction. amount of lateral electron injection to AlGaN surface. Fur-
line, consistent with 2D-VRH conduction.
Downloaded 28 Aug 2007 to 133.87.129.235. Redistribution subject to AlP license or copyright, see http://apl.aip.org/apl/copyright.jsp

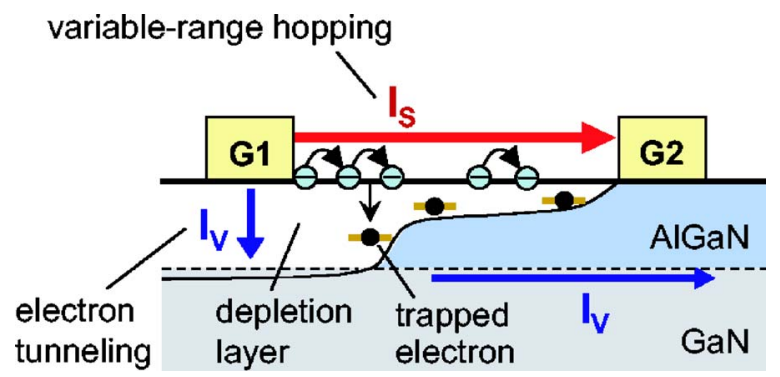

FIG. 4. (Color online) Two-dimensional variable-range hopping along AlGaN surface in the vicinity of Schottky gate.

$200 \mu \mathrm{m}-600 \mu \mathrm{m}$ and proposed a model based on surface donor. ${ }^{8,9}$ Here, the width of the Schottky barrier was assumed to be reduced due to the presence of unintentionally introduced surface donors, such as nitrogen vacancy defects or oxygen impurities. ${ }^{10,11}$ This results in temperature independent large tunneling current. Thus, weak temperature dependence observed in $I_{v}$ indicates that the leakage current transport for large area Schottky contacts is still working even in $1 \mu \mathrm{m}$ Schottky gates for $I_{v}$.

However, a clear temperature dependence appeared in $I_{s}$, indicating not a tunneling mechanism but some other thermally activated conduction mechanism. One of the possible mechanisms for surface current is two-dimensional variablerange hopping ${ }^{12}$ (2D-VRH) assisted by a high-density surface electronic state in $\mathrm{AlGaN}$. The temperature dependence of conductivity based on 2D-VRH is theoretically given by the following simple expression: ${ }^{12}$

$$
\sigma(T) \propto \exp \left[-(1 / T)^{1 / 3}\right] .
$$

Figure 3(b) shows the temperature dependence of the surface current at $V_{\mathrm{G}}=-2 \mathrm{~V}$ as a function of $1 / T^{1 / 3}$. The $I_{s}$ plotted in Fig. 3(b) gives a straight line for temperatures from 100 to $300 \mathrm{~K}$, showing the characteristic temperature dependence of $2 \mathrm{D}-\mathrm{VRH}$ proportional to $\exp \left(-1 / T^{1 / 3}\right)$. Other devices with different $L_{\mathrm{GG}}$ of $200 \mathrm{~nm}$ and $1 \mu \mathrm{m}$ also showed the same temperature dependence of $I_{s}$. These results confirm that 2D-VRH governs surface current transport in the vicinity of Schottky gates.

Figure 4 shows a model for the leakage current transport in the vicinity of Schottky gates. In addition to the occurrence of the vertical tunneling current, the lateral electron injection to the high-density surface electronic states on the AlGaN surface occurs through electron tunneling at the edge of G1 due to electric field concentration at the gate edge. These laterally injected electrons propagate toward G2, assisted by the 2D-VRH conduction through high-density Al$\mathrm{GaN}$ surface electronic states. Although the reason for the $L_{\mathrm{GG}}$ dependence of $I_{s}$ is not clear yet, we discuss the possible mechanisms to explain the drastic increase in $I_{s}$ shown in Fig. 2(b).

First, by considering deep levels in AlGaN, it is likely that some of surface hopping electrons are trapped by the deep levels. Reducing $L_{\mathrm{GG}}$ may increase the numbers of electrons which reach to $\mathrm{G} 2$ due to less possibility of electron capture by the deep traps, resulting in increase in $I_{s}$. Second, a difference in lateral electron injection rate at G1 gate edge may exist among the devices with different $L_{\mathrm{GG}}$. Higher electric field is induced at G1 gate edge in the devices with shorter $L_{\mathrm{GG}}$ under the same $V_{\mathrm{G}}$ of $-4 \mathrm{~V}$, resulting in larger 


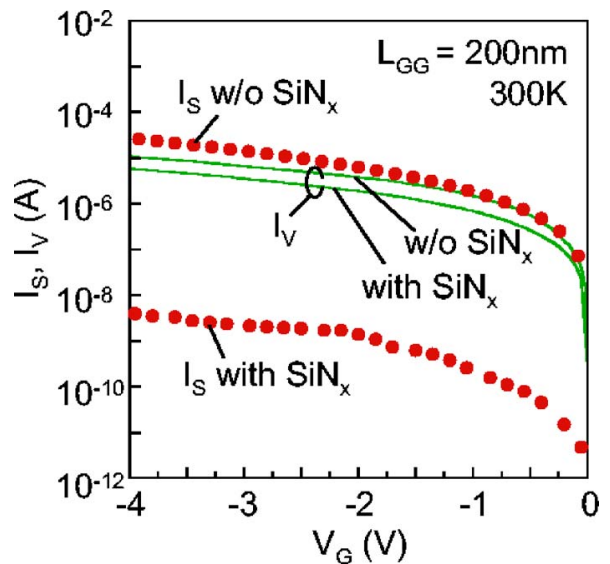

FIG. 5. (Color online) Effect of $\mathrm{SiN}_{x}$ passivation on $I_{s}-V_{\mathrm{G}}$ and $I_{v}-V_{\mathrm{G}}$ characteristics.

thermore, the average electric field at AlGaN surface between G1 and G2 electrodes also increases with decreasing $L_{\mathrm{GG}}$. This may lead to the potential lowering of the hopping states, called Poole-Frenkel effect, thereby enhancing the 2D-VRH process toward G2. This also can increase the surface current at shorter $L_{\mathrm{GG}}$.

Finally, we investigated the $\mathrm{SiN}_{x}$ passivation effect on surface leakage current. The $\operatorname{SiN}_{x}$ layer was chosen because it is most commonly used as a passivation layer for $\mathrm{AlGaN} / \mathrm{GaN}$ HEMTs and is very effective in removing current collapse. Prior to depositing $\mathrm{SiN}_{x}$, we conducted nitrogen plasma treatment for $5 \mathrm{~min}$ at a substrate temperature of $260{ }^{\circ} \mathrm{C}$ to clean the surface and recover the nitrogen vacancy. ${ }^{13,14}$ A 20 -nm-thick $\operatorname{SiN}_{x}$ layer was deposited sequentially by using electron cyclotron resonance-assisted chemical vapor deposition with a mixture of $\mathrm{SiH}_{4} / \mathrm{N}_{2}$ gas at $260{ }^{\circ} \mathrm{C}$.

Figure 5 shows the $I_{s}-V_{\mathrm{G}}$ and $I_{v}-V_{\mathrm{G}}$ characteristics before and after the $\operatorname{SiN}_{x}$ passivation. As shown in Fig. 5, the vertical current remained virtually unchanged before and after the passivation, reflecting that the surface process does not affect the properties of the embedded Schottky interface. However, a pronounced reduction in surface current of al- most four orders of magnitude was observed after the $\mathrm{SiN}_{x}$ passivation. The passivation effectively reduces the density in surface electronic states on the $\mathrm{AlGaN}$ surface, thereby resulting in suppression of the surface leakage transport.

In conclusion, we systematically investigated the lateral surface leakage current on an $\mathrm{AlGaN} / \mathrm{GaN}$ heterostructure by using a two-parallel gate structure with a gap distance $\left(L_{\mathrm{GG}}\right)$ of $200 \mathrm{~nm}-5 \mu \mathrm{m}$. The surface current $I_{s}$ drastically increased as $L_{\mathrm{GG}}$ decreased when $L_{\mathrm{GG}}$ reduced to less than $1 \mu \mathrm{m}$. A simple resistive layer conduction, which should have $1 / L_{\mathrm{GG}}$ dependence, failed to account for this anomalous behavior in $I_{s}$. However, no dependence on $L_{\mathrm{GG}}$ was seen in vertical current $I_{v}$. The $I_{s}$ showed clear temperature dependence proportional to $\exp \left(-T^{-1 / 3}\right)$, indicating twodimensional variable-range hopping through high-density surface electronic states in $\mathrm{AlGaN}$. A pronounced reduction in surface current of almost four orders of magnitude was observed in the sample with the $\operatorname{SiN}_{x}$ passivation.

${ }^{1}$ M. Higashiwaki, T. Mimura, and T. Matsui, Jpn. J. Appl. Phys., Part 2 45, L1111 (2006).

${ }^{2}$ A. Endoh, Y. Yamashita, K. Ikeda, M. Higashiwaki, K. Hikosaka, T. Matsui, S. Hiyamizu, and T. Mimura, Phys. Status Solidi C 0, 2368 (2003).

${ }^{3}$ A. V. Vertiatchikh and L. F. Eastman, Electron. Lett. 39, 876 (2003).

${ }^{4}$ J. Kotani, S. Kasai, T. Hashizume, and H. Hasegawa, J. Vac. Sci. Technol. B 23, 1799 (2005).

${ }^{5}$ W. S. Tan, M. J. Uren, P. A. Houston, R. T. Green, R. S. Balmer, and T. Martin, IEEE Electron Device Lett. 27, 1 (2006).

${ }^{6}$ H. Hasegawa, T. Muranaka, S. Kasai, and T. Hashizume, Jpn. J. Appl. Phys., Part 1 42, 2375 (2003).

${ }^{7}$ T. Hashizume, J. Kotani, A. Basile, and M. Kaneko, Jpn. J. Appl. Phys., Part 2 45, L111 (2006).

${ }^{8}$ J. Kotani, T. Hashizume, and H. Hasegawa, J. Vac. Sci. Technol. B 22, 2179 (2004).

${ }^{9}$ J. Kotani, M. Kaneko, H. Hasegawa, and T. Hashizume, J. Vac. Sci. Technol. B 24, 2148 (2006).

${ }^{10}$ T. L. Tansley and R. J. Egan, Phys. Rev. B 45, 10942 (1992).

${ }^{11}$ K. H. Ploog and O. Brandt, J. Vac. Sci. Technol. A 16, 1609 (1998).

${ }^{12}$ N. F. Mott and E. A. Davis, Electronic Process in Non-Crystalline Materials, 2nd edition (Clarendon, Oxford, 1979), p. 32.

${ }^{13}$ T. Hashizume and R. Nakasaki, Appl. Phys. Lett. 80, 4564 (2002).

${ }^{14}$ T. Hashizume and H. Hasegawa, Appl. Surf. Sci. 234, 387 (2004). 